\title{
INCLUSÃO DO JOVEM DE BAIXA RENDA NA UNIVERSIDADE ATRAVÉS DO DESIGN
}

\author{
Marina L. Moreira \\ PUC-Rio \\ marinamoreira@hotmail.com \\ Daniel Moura Nogueira \\ PUC-Rio \\ daniel.m.nogueira@gmail.com \\ Fernanda Pina \\ PUC-Rio \\ pina.fernanda@gmail.com \\ Janara Morenna \\ PUC-Rio \\ janaramorenna@yahoo.com.br
}

Resumo: Este trabalho é o resultado de uma investigação das experiências e trocas entre o jovem oriundo de comunidades de baixa renda e o ambiente universitário. Partindo de questões relativas à interdisciplinaridade, debatidas ao longo da disciplina "Design e Interdisciplinaridade" da Pós Graduação do Departamento de Artes de Design da PUC-Rio, no segundo semestre de 2015. O Design é usado como ferramenta de abordagem de problemas complexos e oportunidades derivadas da relação jovem $x$ universidade - circunscrevendo uma tríade entre Design, Interdisciplinaridade e Complexidade. A coleta de dados envolveu uma parceria com o NEAM (Núcleo de Estudos e Ação sobre o Menor) e o LILD (Laboratório de Investigação em Living Design), na PUCRio. Foram analisados conteúdos de cartas originárias de uma atividade multidisciplinar anterior, o projeto Ninho-Domo. Em seguida, foram entrevistados, por meio de roteiros semi-estruturados, cinco jovens vinculados ao NEAM de diferentes comunidades. Como fundamentação teórica e referências bibliográficas, dentre os principais autores e publicações estão: Edgar Morin (2013), sobre o Pensamento Complexo; Rômulo Costa Mattos (2010), sobre as favelas e seu histórico; bem como dados do IBGE e documentos dos arquivos do NEAM e LILD. Os resultados desta investigação indicam que por meio das ações projetuais do design associadas à interdiciplinaridade permitiu identitificar potencial transformador nos jovens vinculados a esses núcleos, independente de sua origem socioeconomica.

Palavras-chave: Design, Interdisciplinaridade, jovem, baixa renda. 


\begin{abstract}
This article is the result of an investigation of experiences and exchanges between youths from low-income communities and the university environment, from the perspective of complex problems. Starting with issues of interdisciplinarity, discussed over the course "Design and Interdisciplinarity" of the Postgraduation Department of Art Design at PUCRio, over the second half of 2015, Design is used as a tool to address the complex issues and opportunities derived from the relationship between youths and university - circumscribing a triad amongst Design, Interdisciplinarity and Complexity. Data collection involved a partnership with NEAM (Center for Research and Action on Minor) and LILD (Research Laboratory in Living Design) at PUC-Rio. Letters from a previous multidisciplinary activity, the nest-Dome project, were analyzed and interviews, using semi-structured scripts, were made with five young people linked to NEAM, of different communities. As theoretical background and references, among the main authors and publications are: Edgar Morin (2013), on the Complex Thought; Romulo Costa Mattos (2010) on the slum and its history; and IBGE data and documents NEAM and LILD files. The results of this research indicate that through the projectual actions of the design associated with interdiciplinarity allowed the identification of a transformative potential in young people linked to these nuclei, independently of their socioeconomic origin.
\end{abstract}

Keywords: Design, Interdisciplinarity, youth, low-income.

\title{
1. INTRODUÇÃO
}

Este trabalho é resultado de uma imersão sobre os conceitos que abarcam a questão da Interdisciplinaridade discutidos durante a disciplina de Design e Interdisciplinaridade, ministrada no programa de Pós Graduação do Departamento de Artes e Design da PUC-Rio, no segundo semestre de 2015. Partindo do pressuposto que o próprio termo "interdisciplinaridade" carrega uma série de enunciados dotados de diversas acepções e relações, o termo ainda não possui um sentido epistemológico fechado ou definitivo.

Desde o início, notamos a necessidade de novos questionamentos, de uma mudança de atitude na abordagem do objeto de pesquisa, de forma a observar o conjunto como um todo. Daí a relevância da interdisciplinaridade e não de uma fragmentação dos saberes. De acordo com Couto (1997), novos questionamentos surgem por conta da interdisciplinaridade, que implicam em uma mudança de atitude, visando uma compreensão mais ampla da realidade.

Neste trabalho escolhemos usar o termo dando ideia de ação/ processo / maneira de ligar e religar as ciências ou as próprias ações e processos em um sentido de relação horizontal que contempla o resultado do "todo", motivo este da nossa escolha pelo autor Edgar Morin (2001), pai do Pensamento Complexo. Para dar o tom nessa "costura" que transpassa a atividade acadêmica, de pesquisa, projetos sociais ou o papel da universidade na cultura e na sociedade; decidiu-se por realizar este trabalho propondo um método customizado para dar conta das nossas premissas, a saber: 
1 - A Comunidade considerada de baixa renda e suas oportunidades de transformação quando se tem acesso a novas possibilidades. Consideramos a cultura e a educação como combustível para a exploração destas novas oportunidades.

2 - Os jovens investigados e suas comunidades, a relação deles com a Universidade, sendo esta um celeiro de oportunidades e aplicação do que se aprende no ambiente universitário no seu dia a dia, destacando a consciência que esses jovens passam a ter da Universidade como aquela que subsidia sua formação como agente transformador.

3 - A missão maior da universidade - de universalizar as relações humanas, por meio das questões Complexas, sob a ótica do Design, sendo estas questões a representação das oportunidades do jovem que vive em comunidades de baixa renda.

4 - A parceria entre NEAM (Núcleo de Estudo e Ação sobre o Menor) e o LILD (Laboratório de Investigação em Living Design da PUC-Rio) como um provedor de experiências dentro do ambiente universitário em diversas esferas: educação, cultura, design, arte, etc.

O Design, por sua vocação interdisciplinar, permeou a elaboração dos mecanismos de abordagem, coleta de dados, entrevistas e demais experimentos necessários para o desenvolvimento deste trabalho. A prática do Design demanda, além de conhecimentos técnicos, considerações sobre o universo dos usuários em contato com seus produtos e serviços. Para tal, conhecimentos diversos podem ser explorados simultaneamente durante o processo projetual, tais como psicologia, estética, antropologia, ergonomia, marketing, informática, economia, semiótica etc. Essa natureza diversa, em constante contato com múltiplas disciplinas, torna o Design uma ferramenta condizente com uma abordagem interdisciplinar, objetivo desta investigação.

O objetivo principal deste trabalho foi o de propor um olhar sobre o jovem como agente transformador do seu ambiente por meio de experiências vividas no ambiente universitário através de ações que contemplem uma postura interdisciplinar conectando projetos em andamento na Universidade. Com a intenção de abranger as mais diversas comunidades da cidade do Rio de Janeiro, mas sem a pretensão de contemplar todas, foram selecionados jovens residentes em comunidades distintas das seguintes localidades: Vidigal, Gávea, Pavuna, Bonsucesso e Jacarepaguá. É preciso reforçar o caráter exploratório deste estudo, que não pretende limitar suas conclusões no que tange as oportunidades de relação entre jovens carentes e o ambiente universitário.

Quando o assunto são os problemas sociais versus as ações realizadas por iniciativas do Segundo e Terceiro setores, as opiniões são diversas. Muitos apoiam que qualquer ação em prol de uma mudança pela igualdade social seja benéfica para todos, inclusive os que se dizem contra tais iniciativas, pois até os mais egoístas são beneficiados quando a sociedade se equilibra em termos de igualdade de oportunidades nas esferas social e econômica. Para entender um pouco desse estigma direcionado aos moradores de áreas favelizadas, nada melhor que recorrer à História: a partir da informação sobre a formação das favelas e das discussões em torno deste fenômeno ao longo do tempo podemos entender melhor os desafios atuais para que possamos de fato construir um ambiente mais justo e harmônico. 
Segundo o IBGE (2000) o número de moradores de favelas cresceu na velocidade de 2.6 vezes maior que a população total. Ainda segundo o órgão, a população total com dados de 2001 era de 1.100 .000 habitantes no Rio de Janeiro, sendo a população total da cidade de 5.857 .904 habitantes. Tal crescimento fez com que a favela virasse pauta e novas iniciativas do governo começassem a surgir, sempre no intuito de conter o crescimento com base nos impactos gerados que vão desde o ambiental (que antigamente vinha da ideia do higienismo), como também o combate ao tráfico e a violência urbana.

Vale destacar que a questão da valorização imobiliária sempre esteve estreitamente ligada às ações de contenção e exclusão de favelas, como foi o caso da favela do Pinto - no Leblon, erradicada em 1969. "A favela localizava-se no Leblon, onde moravam cerca de 20 mil habitantes. Segundo jornais da época, esta era a maior favela vertical do Brasil" (MATTOS, 2010, apud SANTOS, 2010).

De lá para cá muitos programas foram criados com o objetivo de melhorar a infraestrutura e fornecimento de bens básicos como energia e saneamento, regulamentação fundiária, "Favela Bairro".

Em 2008 houve o plano de "Pacificação" com as UPP's - considerado um dos programas mais importantes de segurança pública do Rio de Janeiro. Projeto este que coloca questões contraditórias em pauta - por um lado há os que defendem com base nos dados da diminuição da violência e tráfico de drogas, por outro há os que questionam a repressão e violência policial. É neste ambiente antagônico, intrincado e com diversos obstáculos de socialização e dignidade humana que muitos dos jovens atendidos pelo NEAM, instituído e mantido pela PUC-Rio, se encontram. Essa realidade esta cada vez mais próxima a todos que já não podem mais ignorar a importância das relações entre todas as esferas da cidade, motivo pelo qual surgem movimentos e mudanças de paradigmas e integração através da cultura, da arte, do esporte e da educação.

Neste contexto, os jovens entrevistados para este estudo, vindos das favelas ou de comunidades semelhantes, demonstram profundo sentimento de gratidão pelas oportunidades apresentadas quando são inseridos em outros contextos de vida como em um ambiente acadêmico, onde aprendem que merecem uma vida mais digna, que merecem respeito e devem lutar pelos seus sonhos, mas para sonharem precisam saber que podem contar com uma estrutura que os apoie em seus projetos antes impensáveis.

\section{DESENVOLVIMENTO}

No decorrer do desenvolvimento da pesquisa decidimos escolher uma prática educacional aplicada e que já tinha um método investigativo desenvolvido com estes jovens. Que chamamos de 10 feedback.

O 1ㅇ feedback baseou-se em uma atividade multidisciplinar, sem relação direta com práticas educacionais formais, que promovia a intenção e aproveitamento de ensinamentos. Acreditava-se que atividades como estas poderiam incentivar futuro das escolhas acadêmicas dos jovens, uma vez, que os jovens envolvidos se encontram dentro da universidade. A esta atividade deu-se o nome de Ninho-Domo. Os ensinamentos transmitidos apoiavam a construção da Casa do João de Barro, onde os 
jovens as colocariam em Tínguá (Nova Iguaçu - RJ). Após esta experiência, os jovens foram convidados a escrever cartas sobre o que eles aprenderam. Para este trabalho o 1o feedback limita-se a análise de tais cartas que tanto contribuiu para nossas conclusões, como também para nos ajudar a desenvolver um roteiro que seria aplicado em entrevistas individuais.

O 2o feedback nos ajudaria a refletir junto com o jovem sobre o papel que a universidade passava a ocupar na sua vida.

Durante esta etapa não tínhamos a intenção de retomar a intervenção NinhoDomo. Para este trabalho, esta atividade serviu para delimitar uma experiência vivida no ambiente universitário. Construir a casa do João de barro colocava o jovem diante de uma situação aparentemente complexa, sem que eles percebessem de imediato a dimensão do legado que obteriam. No 2ㅇ feedback nós desejávamos entender como o jovem se enxergava antes e depois de começar a frequentar a universidade.

Por meio de um roteiro semiestruturado coletamos depoimentos dos jovens sobre suas motivações a partir das novas vivências, quais seus sonhos e planos futuros, estimulando-os a falarem sobre como eles passaram a influenciar ambientes e pessoas dos seus contextos de vida.

Desta forma, deixamos esta primeira fase que contemplava um entendimento prévio sobre quais os métodos adequados para os objetivos propostos, rumo à segunda fase com foco no melhor entendimento sobre o perfil destes jovens.

\subsection{Perfil dos Candidatos}

Os cinco jovens entrevistados foram selecionados ${ }^{1}$, usando como principal critério seus vínculos ao NEAM e sua participação em atividades interdisciplinares promovidas pela universidade por meio do LILD, neste caso batizada de Ninho-Domo. Outras características que configuram este grupo eram: serem alunos matriculados em diferentes escolas públicas do Rio de Janeiro para assegurar um grupo heterogêneo. Todos estavam regularmente matriculados entre o 90 ano (ensino fundamental II) e 3 은 ano do ensino médio e tinham entre 15 e 17 anos de idade. 0 quadro a seguir apresenta quem são esses jovens.

\begin{tabular}{|c|c|c|c|c|}
\hline Jovem & Residente & Ano escolar & Tempo de NEAM & Idade \\
\hline Rafael & Jacarepaguá (Comunidade da Cidade de Deus) & $1^{\circ}$ ano & 6 meses & 15 \\
\hline Patrick & Gávea (Conj. Hab. Marquês de São Vicente, conhecido como Minhocão) & $1^{\circ}$ ano & 4 anos & 17 \\
\hline Daniel & Leblon (Morro do Vidigal) & $9^{\circ}$ ano & 4 anos & 17 \\
\hline Denison & Bonsucesso & $9^{\circ}$ ano & 1 ano & 15 \\
\hline João Vitor & Pavuna & $2^{\circ}$ ano & 2 anos & 16 \\
\hline
\end{tabular}

Figura 1 - Perfil dos jovens entrevistados.

Fonte: Elaborado pelo autor, com base na pesquisa realizada.

${ }^{1}$ Cabe ressaltar que, para este trabalho, optou-se pela inclusão dos relatos de dois dos cinco jovens selecionados (Rafael e Patrick, nos itens 3.1. e 3.2. respectivamente), para que o conteúdo obedeça o limite de páginas estabelecido pelo P\&D 2016. 
Uma vez entendido o perfil dos nossos entrevistados e os procedimentos metodológicos adequados, seguimos com o roteiro pré-estabelecido na expectativa de coletarmos e analisarmos os dados que seriam obtidos. No entanto, antes de entender o que havia por trás de tais falas, foi importante entender como se deu a coleta dos dados.

\subsection{Coleta dos Dados}

A partir das cartas anteriormente mencionadas, buscamos a compreensão do jovem, após a submissão deles a uma intervenção utilizando processos do design com base nos conceitos da interdisciplinaridade sem um objetivo acadêmico pré-definido. Diante das entrevistas buscamos uma compreensão sobre a percepção do jovem sobre a importância da vivência em um ambiente acadêmico.

Cientes da necessidade em obter o 1 - feedback, selecionamos trechos que indicassem a importância percebida para o jovem de ter participado da atividade Ninho-Domo. Juntos recortamos trechos que nos ajudavam a estruturar um roteiro para segunda fase metodológica.

Uma vez entendido que precisávamos entrevistar os jovens buscando algumas respostas específicas para ter o 2 - feedback, decidimos nos reunir novamente com os mentores do Ninho Domo e a coordenação do NEAM. Nesta etapa, a pesquisadora que também é coordenadora no núcleo, não poderia participar das entrevistas, já que para os entrevistados existe um vínculo que poderia influenciar nos resultados. Passamos a nos questionar se a entrevista deveria ser feita pelos outros participantes ou se deveríamos eleger somente um, diante do perfil heterogêneo do grupo e com os objetivos da entrevista. Optou-se pela pesquisadora Fernanda Pina tendo em vista que esta também possui filho adolescente, tal experiência contribuiria em aspectos como a linguagem e narrativa adequada no contato com os jovens.

De acordo com Morin (2013), a ordem e a desordem estão inseparadas, havia uma expectativa em torno do que achávamos que obteríamos de resultados: partimos do pressuposto que todos estes jovens falam pouco e sentem-se desconfortáveis ao falar de si. Contudo, nos surpreendemos com os longos relatos. Até o momento não temos ao certo a justificativa de por que esses jovens falaram tanto nas entrevistas.

Acreditamos que o fato da entrevistadora ser mãe de um jovem, como mencionado, pode ter contribuído somado ao fato dela também ter sido uma jovem de comunidade que buscava oportunidades. Por fim, o simples fato dela ser uma desconhecida, não tendo nenhum papel definido no imaginário que tange papéis sociais aos quais os entrevistados estão submetidos, podem ter contribuído como oportunidade para um relato com maior despojamento e entrega.

Os trechos representativos destas entrevistas foram relacionados com trechos das cartas, o que iluminou muito a visão de todos nós, inclusive da coordenadora no NEAM. Nas análises dos métodos aqui empregados deixaremos mais claro com esta relação foi feita e o quão representativo isto nos pareceu. 


\section{ANÁLISE E DISCUSSÃO DOS RESULTADOS}

Além dos jovens selecionados para este trabalho viverem em comunidades diferentes e, portanto, estarem sujeitos as mais diversas influências, é possível perceber como estes jovens são diferentes. Ainda assim, todos são "típicos jovens".

Mas qual é o perfil do jovem de hoje? Teríamos um perfil genérico que abrace o imaginário sobre o jovem? E esse perfil também se aplicaria ao jovem de baixa renda? São muitas inquietações que também nos acompanharam. Entender que elas existem foi fundamental para manter a imparcialidade e nos orientar para considerar quem são esses meninos. Cada um com sua própria individualidade, com seus próprios sonhos diante da sua própria realidade.

No presente trabalho, serão apresentados os resultados da entrevista de dois jovens: Rafael e Patrick. Se o leitor tiver interesse em conhecer com mais detalhes o trabalho que foi desenvolvido, disponibilizamos o trabalho em versão completa, sendo necessário somente o contato conosco por e-mail.

\subsection{Rafael: $o$ ator que canta ou o cantor que interpreta? Eis a questão.}

Rafael, dezesseis anos, morador da Cidade de Deus e cheio de planos. Chegou ao NEAM no início de 2015 e, portanto, atendido há seis meses. Como ele mesmo diz, já é outra pessoa. Em sua carta, após a experiência do Ninho-Domo, quanto em sua entrevista percebemos estar diante de uma pessoa que ampliou seu campo de visão. Aliás, esta visão mais ampla de mundo intricado, mas que também amplia as oportunidades é uma característica típica de todos os entrevistados, mas em Rafael ela é mais forte. Isto pode estar atrelado a sua recém-chegada ao NEAM, ou ao fato de conseguir ter acesso a oportunidades jamais pensadas e não querer perder tempo para por seus planos em ação.

O jovem chegou ao NEAM por indicação de uma amiga que também faz parte do núcleo. Para ele, a oportunidade de ocupar o tempo ocioso foi o que mais the atraiu. "Chegar em casa da escola e não ter nada para fazer não é bom", segundo Rafael. Ele também pensa em conquistar sua independência financeira e sabia que estando no NEAM essa conquista seria mais fácil, já que o núcleo prepara todos os seus atendidos para serem jovens aprendizes e, consequentemente, terem uma renda própria. Estar no NEAM também era ter novos acessos. Um novo ambiente, novas pessoas e novas oportunidades que, segundo nosso entrevistado, o fez ser muito diferente do que é. No trecho a seguir, podemos perceber como Rafael entende o que é estar no NEAM:

Hoje eu saio do colégio e venho direto pra cá. Antes de vir pra cá, eu era muito tímido, vivia fechado, não falava com ninguém. Agora eu melhorei muito. Até uma professora da minha escola me elogiou. Eu tenho uma banda com alguns colegas lá onde eu moro, também faço teatro e quero tentar manter as duas profissões.

Quando questionado se antes de entrar para o NEAM o seu sonho era o mesmo do que o de hoje, Rafael afirma, com conviç̧ão, que antes não sonhava com nada. Ele até se animava com a banda, mas não acreditava muito. Hoje ele aparenta se um líder nato. Diz que orienta os amigos na aquisição dos instrumentos. Ele próprio deu 
exemplo e hoje já possuiu seu baixo. Agora está "em cima de um amigo que não quer comprar a batera".

Rafael argumenta que ele e os membros da banda têm que começar cada um fazendo sua parte: "é o nosso sacrifício para conquistar alguma coisa". É pensando assim que ele acredita que vai ter a banda dele fazendo shows, mas que acha que o teatro vai complementar melhor sua renda, além de facilitar a divulgação da banda, que é de rock que diz que não é o gosto da maioria das pessoas.

Depois de viver o Ninho-Domo, o músico Rafael mostrou-se, em sua carta, otimista com o aprendizado vivido, assim como se mostra otimista com as novas oportunidades relatadas na entrevista. O trecho a seguir, extraído da carta, indica suas impressões sobre o projeto que ele participou no LILD:

O Professor A me ensinou que o barro pode ser útil para muitas coisas. (...) Bambu também pode ser usado para criar várias coisas: bicicletas, cabanas e outras estruturas que podem ser aproveitadas no mercado de construção, artesanatos e outros. É uma maneira muito diferente de ver as construções de vários modelos ou protótipos.

Sem que, em nenhum momento, ele fosse questionado, na entrevista sobre o Ninho-Domo, Rafael falou do projeto como algo que "foi muito maneiro", exemplificando como sua passagem pelo NEAM tem sido importante para que ele se torne uma pessoa melhor. Segundo ele, além da timidez, já superada, Rafael também se acha mais criativo e responsável. Para sua mãe e outras pessoas da família essa mudança é perceptível. Já para os colegas de banda, Rafael passou a ser uma referência e como ele mesmo diz: "ano que vem meus amigos vão tentar entrar aqui.".

Se Rafael levar adiante este otimismo que, para nós pesquisadores é fruto das intervenções proporcionadas pelo NEAM, ele tentará ser uma referência também quando o assunto for um show de rock ou uma peça de teatro. Para resumir a visão do nosso músico ator, ou ator músico, sobre sua atual experiência, pedimos que ele apontasse uma palavra ou expressão para cada um dos termos indicados. Para o NEAM, ele não pestanejou e falou prontamente a palavra esperança, para PUC-Rio, com a mesma agilidade falou oportunidade e para LILD, ele primeiro perguntou do que se tratava e a entrevistadora falou ser o laboratório onde ele fez o experimento NinhoDomo, após um riso espontâneo, ele disse não tinha como não responder Professor $A$.

\subsection{Patrick: mais que um ilustrador, o poeta dos traços.}

Patrick é mais um caso emblemático do NEAM. Atualmente vive seus últimos dias como menor atendido, já que é política do núcleo suspender o atendimento quando se atinge dezoito anos. Por isso, este jovem tem muita história de superação e conquistas para contar. Ao contrário de Rafael, Patrick é mais centrado e nitidamente mais amadurecido. No entanto, mantém o mesmo otimismo com seus planos de vida.

No seu ciclo de amizade era comum ter um colega que já tivesse passado ou tivesse o interesse de passar pelo NEAM. No caso de Parick a voz do primo, também atendido pelo Núcleo falou mais alto. $O$ fato de já desenhar e querer aprimorar este talento, fez com que Patrick chegasse até ao NEAM. Ao conhecer Fernando, um dos 
mentores e também ilustrador, o jovem viu ali o início de uma grande amizade que lhe permitiria muitas trocas.

Patrick não esconde que sua paixão é desenhar, tanto que ele acabou também ministrando aulas de desenho na oficina de ilustração, também promovida pelo Núcleo. Durante seus quatro anos de vínculo com o NEAM, Patrick diz já ter passado por inúmeras experiências e que sempre fez questão de levar adiante: a exemplo, o jovem relata como foi aprender, ensinar e usar no seu dia a dia os ensinamentos sobre como fazer cadernos. Para ele aprender a fazer caderno não se limita a aprender um trabalho manual, significa da forma a algo útil e a "aprender outras coisas que vem junto". Patrick disse ter um ano escolar, que todos os seus cadernos foram feitos por ele mesmo, disse que ainda ajudou muitos colegas a fazerem o mesmo e a dividir a consciência do reaproveitamento de materiais, além de contar com algo personalizado.

Ele alega não fazer planos para o futuro, mas relata coisas que não quer deixar de fazer. Patrick quer voltar a Europa viajar por alguns países e tentar trabalhar como tatuador, depois de se formar em Design pela PUC-Rio. Segundo o rapaz, antes de estar no NEAM ele projetava ser um grafiteiro. Em 2013, Patrick esteve no sul da França com sua mãe que hoje vive lá depois de compor uma nova família. Durante um ano o menino fez diversos cursos de desenho, mas que segundo ele não foram tão bons quanto os ensinamento do Fernando. Disse não "levar muito jeito com os franceses", Patrick voltou e pediu para se reintegrar ao NEAM. Por desejar não sair da PUC-Rio, que abriu um leque de tantas oportunidades, Patrick atualmente se dedica ao estudo para ingressar na universidade através do vestibular.

Sua visão amadurecida e apaixonada pelo NEAM o faz participar de todas as atividades propostas e saber aproveitar ao máximo. Segundo o ilustrador, muitas vezes a gente começa uma atividade sem saber o que vai acontecer, mas depois a gente percebe o quanto aprendeu. Não atoa, Patrick estava no grupo do Ninho-Domo e um trecho de sua carta exemplifica e reforça a maneira como ele vê as atividades promovidas pelo NEAM.

Quando se trata do barro podemos destacar que serve para muitas coisas. Uma delas é a fusão do barro com a fibra, que cria uma resistência na fabricação de revestimento para ser utilizado, por exemplo, na casa do João de Barro. (...) O bambu também foi um tema que tivemos e aprendemos sobre sua grande utilidade na construção de casas, tendas, barcos, armários, cadeiras e outros utensílios. É uma experiência muita boa e já posso usar algum conhecimento na escola e nas minhas aulas do ensino médio.

$\mathrm{Na}$ entrevista, Patrick enfatiza que o conhecimento aplicado, de tudo que ele aprende no NEAM, é para que eles se tornem pessoas melhor, para ele "com o aumento da responsabilidade a gente começa até a se relacionar melhor com as pessoas". Para avó de Patrick o NEAM "é uma maravilha" por fazer de Patrick um menino mais atencioso. O próprio relata que hoje ajuda mais a avó. Antes ele "chegava da escola e ficava no sofá deitado vendo televisão ou desenhando" e hoje ele contribui nas tarefas de casa, sem deixar de fazer o que gosta. Apesar desta visão holística, o jovem pauta sua vida no desenho e na parceria que ele quer que nunca acabe com Fernando. 
O NEAM foi e é muito bom pra mim. Mas ter conhecido o Fernando mudou muita coisa. Ele é mais que um professor pra gente. No desenho ele me ensinou muitas técnicas que eu não sabia e se hoje minhas ilustrações são boas é graças a ele e não ao cursinho que fiz na França. Tanto que de lá a gente nunca deixou de se falar. Eu quero estar sempre por perto, por isso, quero passar no vestibular, porque ai quando eu não tiver mais aqui, eu não vou deixar de estar na PUC-Rio.

Para Patrick NEAM é educação, PUC-Rio é oportunidade e LILD é bambu, barro e aprendizado. Com essa bagagem o jovem quer continuar a vida mostrando sua evolução com os desenhos, alegando que sempre tem o que aprender. Quer que o desenho represente seu carinho pelas pessoas, por isso presenteia todos que admira, seja com um retrato para uma amiga que fez quinze anos, seja para Professora B com a imagem sagrada que ela sustenta na parede da sala. Por fim, o poeta dos traços quer que o desenho seja seu sustento, mas sem abrir mão do prazer que este ofício representa. Como ele mesmo diz: "quero passar a vida desenhando e sendo reconhecido, quem sabe com uma exposição". A entrevistadora então é interrompida, pedindo que a sala fosse liberada para os próximos entrevistados, caso contrário a conversa não teria mais fim e o celular do jovem ainda tinham muitas ilustrações registradas para serem expostas.

\section{CONCLUSÃO}

A investigação realizada neste artigo se deu com o intuito de compreender as relações entre o jovem e o ambiente universitário. $O$ objeto de pesquisa, as experiências, trocas, vivências não poderiam ser abordadas sob uma ótica mecânica, excessivamente fragmentada, essencialmente disciplinar. Tendo em vista essa natureza, notou-se a oportunidade de realizar um trabalho tendo a interdisciplinaridade como fio condutor. Segundo COUTO (1997), a interdisciplinaridade se concretiza por meio de uma mudança de atitude, que se conscientiza ao longo do processo:

“... possibilita o conhecimento, por parte do indivíduo, dos limites de seu saber para poder acolher contribuições de outras disciplinas. Interdisciplinaridade deve ser, pois, entendida antes de tudo, como atitude, pautada pelo rompimento com a postura positivista de fragmentação, visando a compreensão mais ampla da realidade. Através desta postura é que ocorre a interação efetiva, sinônimo do interdisciplinar."

Portanto, tomamos a própria diversidade de formação dos pesquisadores envolvidos neste trabalho (uma administradora, um designer, uma educadora e uma designer especialista em marketing) como uma vantagem e não como um problema. 0 fato de o problema a ser estudado ser de ordem complexa não foi encarado como algo impeditivo, apenas alimentou a segurança de que só observaríamos melhor as oportunidades ao longo da investigação, ao abraçar a experiência e o contato com os entrevistados e núcleos de pesquisa. Ou seja, a premissa do trabalho foi tentar vivenciar a interdisciplinaridade fazendo, agindo, pensando e atuando. Fosse planejando o trabalho, idealizando apresentações e experiências, entrevistas, analisando conteúdo ou retomando caminhos conforme algum item importante nos era apresentado. 
O Design, pela sua natureza diversa, foi fundamental para corroborar com a abordagem desejada. O design e a interdisciplinaridade demandam características similares, tais como a curiosidade, a abertura para o diferente, o novo e a inovação. Para tal, a fragmentação e segmentação demasiada seriam obstáculos para a experiência. Apesar da interdisciplinaridade não refutar completamente o especialismo ou a disciplinaridade em si, questionar essas premissas é algo importante e parte desta atitude. A vocação interdisciplinar do Design auxiliou a metodologia de investigação.

Os resultados observados, tanto de experiências anteriores do NEAM e LILD, quanto do conteúdo extraído das entrevistas mostra que há, sim, um potencial transformador nos jovens vinculados a esses núcleos. No entanto, pela dificuldade em se avaliar e transformar as experiências em números tangíveis, uma demanda comum por órgãos reguladores ou fomentadores de pesquisa, torna-se difícil explicitar a relevância do trabalho realizado por essas instituições. Relevância essa não apenas em mão única, não como atitude etnocêntrica, mas como um benefício tanto para o jovem, sua comunidade, família e, também, para o ambiente universitário como um todo.

A atitude interdisciplinar nos ajudou a viver e aprofundar a importância de abraçar o novo, de encarar a complexidade como vetor de oportunidades, não apenas como um problema "complicado" de se investigar. A análise das entrevistas foi tão importante quanto própria experiência de se realizar as entrevistas. Ou seja, transformar em dados ou números algo que envolve a sensibilidade e a vivência deixou de ser uma das intenções ao longo do processo. Notamos que a experiência da ação não é mensurável, pois cada indivíduo teve a sua troca, seu aprendizado durante a investigação. Apenas desejamos que mais pesquisadores e jovens tenham a oportunidade que tivemos.

\section{REFERÊNCIAS}

COUTINHO, D. Um olhar sobre a produção cultural na Rocinha. Rio de Janeiro. s./n, 2013.

COUTO, R. M. S. Movimento interdisciplinar de designers brasileiros em busca de educação avançada. 1997. Tese. (Doutorado em Educação) - PUC-Rio, Rio de Janeiro, 1997.

- Reflexões sobre “A Possibilidade de uma Teoria do Design”, treze anos depois. Laboratório de Interdisciplinar de Design/Educação da PUC-Rio. Palestra Simpósio LARS, 2008.

FRASCARA, J. Que és el diseño de comunicación? Buenos Aires: Ediciones Infinito, 2011.

JAPIASSU, H. O Sonho Transdisciplinar e as Razões da Filosofia. Rio de Janeiro: Imago, 2006.

KONDER, L. O outro, esse alienígena. O Globo, Rio de Janeiro, 25 de agosto de 1996.

MOREIRA, M. Universidade e Comunidade: a construção de um novo ambiente. Rio de Janeiro: Ed. E-PAPER, 2006.

MORIN, E. Introdução ao Pensamento Complexo. Lisboa: Instituto Piaget, 2001. 